\title{
New Approach for Measuring Antioxidant Activity Via a Graphite Sensor
}

\author{
A. M. El-Kosasy, L. A. Hussien, M. H. Abdel-Rahman* \\ Pharmaceutical Analytical Chemistry Department, Faculty of Pharmacy, Ain Shams University, \\ Abbassia, 11566 Cairo, Egypt
}

Received 16 May 2013; accepted 3 August 2014

\begin{abstract}
An ion selective membrane sensor from dioctyl phthalate as a plasticizer in a polymeric matrix of polyvinyl chloride (PVC) and $\beta$-cyclodextrin as an ionophore was constructed and evaluated according to IUPAC recommendations. Linear Nernstian response of $\mathrm{DPPH}^{*}$ within the concentration ranges of $10^{-6}$ to $10^{-2}$ mol L $\mathrm{L}^{-1}$ was obtained with average recovery $99.87 \pm 0.617$. Nernstian slope of $58.5 \mathrm{mV} /$ decade with excellent selectivity over the $\mathrm{pH}$ range of 3-8 was observed. The suggested method was standardized using butylated hydroxyl anisole (BHA). The 50\% radical scavenging activity $\left(\mathrm{IC}_{50}\right)$ determined by the proposed sensor correlated well with that of the common spectrophotometric method based on scavenging of 2,2-diphenyl-1picrylhydrazyl (DPPH'). An algorithm implemented in Microsoft Visual Basic ${ }^{\circledR} 6.0$ was used for calculating $\left(\mathrm{IC}_{50}\right)$ values which are $7.38 \mu \mathrm{g} / \mathrm{mL} \pm 0.35,89.98 \mu \mathrm{g} / \mathrm{mL} \pm 0.45$ and $1.45 \mathrm{mg} / \mathrm{mL} \pm 1.50$ for BHA, Paracetamol and Dipyridamole, respectively. The proposed sensor represents a simple and reproducible tool for measuring $\mathrm{DPPH}^{\circ}$ scavenging activity of Paracetamol and Dipyridamole in bulk powder, pharmaceutical formulations and simulated intestinal fluid (SIF) without sophisticated separation techniques.
\end{abstract}

Keywords: Sensor, antioxidant, Paracetamol, Dipyridamole.

\section{Introduction}

The chemistry of free radicals and antioxidants is of great importance, particularly in the areas of clinical medicine and nutritional science [1]. Antioxidants act as free radical scavengers and can prevent the damage caused by oxidative reactions, including cancer, Alzheimer's and Parkinson's diseases [2, 3 ,

\footnotetext{
* Corresponding author. E-mail address: monahamdyph@yahoo.com
} 
$4,5,6]$. Hence, the evaluation of the antioxidative activity of medical, cosmetic and food samples provides useful clinical information [7].

One of the most commonly used methods for in vitro evaluation of antioxidant capacity is DPPH• scavenging method $[8,9,10,11,12,13]$. Recently, a number of DPPH• -based tests for the assessment of antioxidant activity have been developed. The evaluation of antioxidant capacity based on the amperometric reduction of DPPH• at the glassy carbon electrode was reported [14, 15], TLC [16], HPLC techniques [17, 18, 19, 20] and flow injection based methods for determination of scavenging capacity against DPPH $\bullet$ were also reported [21, 22, $23,24,25]$. A DPPH• based optical sensor for screening of antioxidant activity was introduced by Steinberg et al. [26].

In the present work, we have studied the feasibility of using a graphite ionselective membrane sensor for evaluation of $\mathrm{DPPH}^{*}$ scavenging activity of certain antioxidants and using BHA, a standard antioxidant, to study its response. The proposed sensor can be considered superior to the common colorimetric method since it can be used for evaluation of antioxidant activity of colored or turbid solutions and it applies neither sophisticated instruments nor any separation step; also, the proposed method is more simple, faster and cheaper than the amperometric and chromatographic methods.

\section{Experimental}

\section{Apparatus}

Mettler Toledo compact titrator model G20 with Labx software version 3.1 accompanied with $\mathrm{Ag} / \mathrm{AgCl}$ double junction reference electrode was used for potential measurements. A Jenway $\mathrm{pH}$ meter $3310 \mathrm{pH} / \mathrm{mV} /{ }^{0} \mathrm{C}$ meter with a Jenway $\mathrm{pH}$ glass electrode (UK) was used for $\mathrm{pH}$ adjustments. Thermostatic multiple water bath, model BT-15 (Spain). Thermometer. Double beam Shimadzu (Japan) 1601Pc UV-VIS spectrophotometer connected to a computer fitted with UVPC personal spectroscopy software version 3.7.

\section{Chemicals and reagents}

2, 2-diphenyl-1-picrylhydrazyl radical (DPPH ${ }^{\circ}$, 99.98\%, was obtained from Sigma Aldrich, Cairo, Egypt. Hepamol ${ }^{\circledR}$ tablets $(500 \mathrm{mg}$ paracetamol/tablet, Hikma Pharmaceutical Company, Egypt) and Persantin tablets (75 mg dipyridamole/ tablet, Sideco Pharmaceutical Company, Egypt).

All reagents and chemicals used throughout this work were of analytical grade and the water used was bi-distilled. Poly (vinyl chloride) carboxylate (PVC carboxylate) and $\beta$-cyclodextrin $(\beta$ - CD) were obtained from Fluka (Chemie Gmbh, Germany), dioctyl phthalate (DOP) was obtained from Aldrich (Germany). Tetrahydrofuran (THF) was obtained from Merck (Darmstadt, Germany). Sodium hydroxide, hydrochloric acid, potassium chloride, citric acid, sodium bicarbonate, nickel chloride hexahydrate and magnesium chloride were obtained from Prolabo (Pennsylvania, USA). Simulated intestinal fluid (SIF) was prepared from $6.8 \mathrm{~g}$ monobasic potassium phosphate, $0.2 \mathrm{M}$ sodium hydroxide 
$(\mathrm{NaOH})$ (to adjust $\mathrm{pH}$ to 6.8 ) and water to $1000 \mathrm{~mL}$ and the temperature was adjusted to $37 \pm 0.2^{\circ} \mathrm{C}$.

\section{Procedures}

Fabrication of the membrane sensor

$0.04 \mathrm{~g}$ of $(\beta-\mathrm{cd})$ was mixed with $0.19 \mathrm{~g}$ PVC carboxylate and dissolved in $0.4 \mathrm{~mL}$ (DOP) and then mixed thoroughly with $5 \mathrm{~mL}$ (THF) till complete homogeneity in a Petri dish (5 cm diameter), the solvent was slowly evaporated at room temperature until an oily concentrated mixture was obtained.

The coated graphite electrode was constructed using a graphite bar $3 \mathrm{~cm}$ length, 3 $\mathrm{mm}$ diameter). One end of the bar was used for connection, while the other, about $1 \mathrm{~cm}$ length, was dipped in the electro-active membrane mixture. The process was repeated several times until a layer of proper thickness was formed covering the terminal of the graphite bar. The electrode was left standing at room temperature to dry. The uncoated end of the graphite rod was sealed in a poly tetra ethylene tube; the tube was filled with metallic mercury into which a copper wire was dipped.

\section{Sensor calibration}

The sensor was conditioned by soaking in $10^{-2} \mathrm{~mol} \mathrm{~L}^{-1} \mathrm{DPPH}^{\bullet}$ solution for only 2 hours before measurement, storage was in distilled water when not in use, the conditioned sensor was calibrated by separately transferring $50 \mathrm{~mL}$ aliquots of solutions covering the concentration range of $\left(10^{-7}\right.$ to $\left.10^{-2} \mathrm{~mol} \mathrm{~L}^{-1}\right) \mathrm{DPPH}^{\circ}$, into a series of $100 \mathrm{~mL}$ beakers. The electrode system was immersed in each solution with constant stirring at speed $20 \%$ in conjunction with a Mettler Toledo reference electrode. The sensor was washed in distilled water between measurements. The sensor potential was plotted versus each negative logarithmic concentration of $\mathrm{DPPH}^{\circ}$, the calibration plot obtained was used for subsequent measurements of unknown samples.

\section{Effect of $\mathrm{pH}$ and temperature}

The influence of $\mathrm{pH}$ on the response of the membrane sensor was checked at various $\mathrm{pH}$ values over a $\mathrm{pH}$ range of (1-9). $1 \times 10^{-3}$ and $1 \times 10^{-4} \mathrm{~mol} \mathrm{~L}^{-1} \mathrm{DPPH}^{\bullet}$ solutions were prepared. Effect of temperature also was checked by applying the same procedures at all concentrations at different temperatures using a water bath and a thermometer to adjust the temperature of each concentration.

\section{Sensor selectivity}

The potentiometric selectivity coefficients $\left(\mathrm{K}^{\mathrm{pot}}\right.$ A.B $)$ of the proposed sensor towards different substances were determined by a separate solution method using the following equation [27]:

$$
-\log \left(K_{A . B}^{p o t}\right)=\left(E_{1}-E_{2}\right) /\left(2.303 R T / Z_{A} F\right)+\left(1-Z_{A} / Z_{B}\right) \log a_{A}
$$

where $\mathrm{K}_{\text {A.B }}^{\text {pot }}$ is the potentiometric selectivity coefficient, $E_{1}$ is the potential measured in $10^{-3} \mathrm{~mol} \mathrm{~L}^{-1} \mathrm{DPPH}^{*}$ solution, $\mathrm{E}_{2}$ is the potential measured in $10^{-3}$ 
mol $\mathrm{L}^{-1}$ of the interfering solution, $\mathrm{Z}_{\mathrm{A}}$ and $\mathrm{Z}_{\mathrm{B}}$ are the charges of $\mathrm{DPPH}^{\bullet}$ and interfering ion, respectively, $\mathrm{a}_{\mathrm{A}}$ is the activity of $\mathrm{DPPH}^{\circ}$ and $2.303 \mathrm{RT} / \mathrm{Z}_{\mathrm{A}} \mathrm{F}$ represents the slope of the investigated sensor ( $\mathrm{mV} /$ concentration decade).

Potentiometric determination of \% DPPH scavenging of pure paracetamol and dipyridamole.

$0.5 \mathrm{~mL}$ of BHA, paracetamol and dipyridamole standard solutions (1.01-15.15 $\left.\mathrm{mg} . \mathrm{mL}^{-1}\right)$ were taken separately to obtain concentrations $(10-150 \mu \mathrm{g} / \mathrm{mL}), 50 \mathrm{~mL}$ $\mathrm{DPPH}^{*}$ working standard solution $\left(1 \times 10^{-4} \mathrm{~mol} \mathrm{~L}^{-1}\right)$ were added, BHA prepared in methanol but paracetamol and dipyridamole prepared in water: methanol $(1: 1)$ then incubated at room temperature for $15 \mathrm{~min}$ after good shaking. Control solutions were prepared, in which no drug was added and the same procedure was carried out. The reagent solutions were prepared daily. Percentages scavenging and $\mathrm{IC}_{50}$ values were calculated using an algorithm [28] implemented in Microsoft Visual Basic ${ }^{\circledR} 6.0$ (Microsoft Corporation, Redmond, WA, USA).The software can be freely downloaded at http://www.pharm.unipmn.it/rinaldi/software/blesq/BLeSq.html. Results were compared with those obtained from the colorimetric method.

Potentiometric determination of $\%$ DPPH ${ }^{*}$ scavenging of paracetamol and dipyridamole in dosage forms

The suggested procedure was applied for the evaluation of $\mathrm{DPPH}^{\bullet}$ scavenging activities of dipyridamole in Persantin ${ }^{\circledR}$ tablets and paracetamol in hepamol ${ }^{\circledR}$ tablets in which ten tablets were weighed and their mean weight was determined. The tablets were finely powdered and accurately weighed portions of powders equivalent to (101.00-1515.00 mg) were transferred to $100-\mathrm{mL}$ volumetric flasks, then the volume was completed with water: methanol $(1: 1)$ then filtered. The same previous procedure was then repeated. Percentages scavenging of paracetamol and dipyridamole in dosage forms, separately, were calculated.

Potentiometric determination of \% DPPH scavenging of paracetamol and dipyridamole in dosage forms in (SIF)

The same procedure was applied but the volume was completed with simulated intestinal fluid (SIF): methanol (1:1) then filtered. Percentages scavenging of paracetamol and dipyridamole in tablet dosage forms, separately, were calculated.

\section{Colorimetric analysis}

The DPPH• scavenging activity was measured by following the methodology described by Sharififar [29] where $50 \mu \mathrm{L}$ of BHA, paracetamol and dipyridamole standard solutions (1.01-15.15 mg.mL $\left.\mathrm{mL}^{-1}\right)$ were taken separately to obtain concentrations $(10-150 \mu \mathrm{g} / \mathrm{mL}), 5 \mathrm{~mL} \mathrm{DPPH}^{*}$ working standard solution $\left(1 \times 10^{-4}\right.$ mol $\mathrm{L}^{-1}$ ) were added, BHA prepared in methanol but paracetamol and dipyridamole prepared in water: methanol (1:1), then incubated at room temperature for $15 \mathrm{~min}$ after good shaking. Absorbances were measured at 517 nm. Control solutions were prepared, in which no sample was added and the 
same procedure was carried out. The assays were carried out in triplicate. The percent radical scavenging activity is determined from the difference in absorbance of $\mathrm{DPPH}^{\circ}$ between the control and samples by the following equation:

$$
\mathrm{I} \%=\left[\left(\mathrm{A}_{0}-\mathrm{A}_{1}\right) / \mathrm{A}_{0}\right] \times 100
$$

where $A_{0}$ is the absorbance of the control reaction and $A_{1}$ is the absorbance in the presence of the antioxidant [30]. The same procedure was applied on pharmaceutical formulations and in SIF.

\section{Results and discussion}

\section{Sensor fabrication}

The central cavity of the cyclodextrin molecule is lined with skeletal carbons and ethereal oxygens of the glucose residues (Fig. 1a). It has therefore lipophilic cavity into which suitably sized drug molecules are included. No covalent bonds are formed or broken during drug-cyclodextrin complex formation [31]. We proposed that the two benzene rings of $\mathrm{DPPH}^{\bullet}$ are located well inside the cavity with the tri nitro benzene group protruding from $\beta$-cd cavity with the formation of hydrogen bonds between hydroxyl groups of $\beta$-cd and nitro groups of $\mathrm{DPPH}^{*}$ (Fig. 1b).
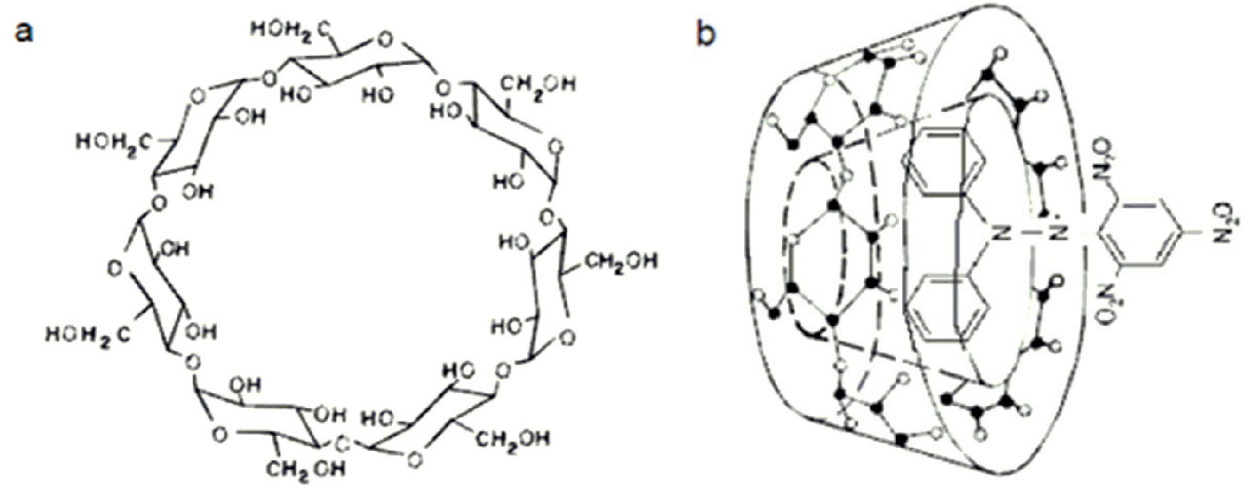

Figure 1. (a) Chemical structure and (b) mode of attachment between $\beta$-cyclodextrin molecule and DPPH*.

It has been reported that PVC matrix is a regular support and reproducible trap for ion association complex in ion selective electrodes [32]. Nevertheless, its use creates a need for plasticization and places a constraint on the choice of the mediator [33].

In the present study, DOP was used in the sensor fabrication, which plasticized the membrane and adjusted permittivity of the final organic membrane [34].

The electrochemical cell of the suggested membrane electrode for the determination of $\mathrm{DPPH}^{\bullet}$ can be illustrated diagrammatically as follows:

Double junction $\mathrm{Ag} / \mathrm{AgCl}$ reference electrodell Test solution (DPPH•)। Membrane (PVC, $\beta-\mathrm{CD}, \mathrm{DOP})$ IGraphite rod॥Metallic mercury. 


\section{Choice of solvent}

The reaction mechanism between $\mathrm{DPPH}^{\circ}$ and antioxidant molecule is based on an electron transfer reaction [35]; as a result, the scavenging capacity against $\mathrm{DPPH}^{\bullet}$ radical is strongly influenced by the solvent and the $\mathrm{pH}$ of the reaction [36]. It was concluded that $50 \%(\mathrm{v} / \mathrm{v})$ aqueous/methanol solutions are a suitable choice for lipophilic and hydrophilic antioxidants and the reaction rate between $\mathrm{DPPH}^{\circ}$ and the antioxidant may increase considerably with increasing water ratios. However, at water content over $60 \%$ (v/v) the measured antioxidant capacity decreased, since a part of the $\mathrm{DPPH}^{\circ}$ coagulates and it is not easily accessible to the reaction with the antioxidant [37].

\section{Sensor calibration and response time}

The electrochemical performance characteristics of the investigated $\mathrm{DPPH}^{\circ}$ selective membrane sensor were evaluated according to IUPAC recommendation data [27] and summarized in Table 1.

Table 1. General characteristics of the proposed DPPH'-selective membrane sensor.

\begin{tabular}{|l|c|}
\hline \multicolumn{1}{|c|}{ Parameter } & Value \\
\hline Slope $(\mathrm{mV} / \text { decade })^{\mathrm{a}}$ & 58.50 \\
\hline Intercept $(\mathrm{mV})$ & 299.2 \\
\hline Correlation coefficient & 0.9995 \\
\hline Response time(Sec.) & 10 \\
\hline Working pH range & $3-8$ \\
\hline Concentration range $(\mathrm{M})$ & $10^{-6}-10^{-2} \mathrm{~mol} \mathrm{~L}^{-1}$ \\
\hline Stability $($ weeks $)$ & 3 \\
\hline Average recovery $(\%) \pm \mathrm{SD}^{\mathrm{b}}$ & $99.87 \pm 0.617$ \\
\hline${\text { LOD }(\mathrm{M})^{\mathrm{c}}}^{\mathrm{c}}$ & $1 \times 10^{-6}$ \\
\hline Repeatability $\left(\mathrm{SD}_{\mathrm{r}}\right)^{\mathrm{d}}$ & 0.540 \\
\hline Intermediate $^{\mathrm{d}}$ precision $_{\left(\mathrm{SD}_{\text {int }}\right)^{\mathrm{e}}}$ & 0.950 \\
\hline Ruggedness $^{\mathrm{c}}$ & $99.80 \pm 0.840$ \\
\hline
\end{tabular}

a, d, e Average of three determinations ${ }^{\mathrm{c}}$ Limit of detection ( measured by interception of the extrapolated arms of Fig .2. ${ }^{b}$ Average recovery percent of determining $10^{-4}, 10^{-3}, 10^{-2} \mathrm{~mol} \mathrm{~L}^{-1} \mathrm{DPPH}^{*}$ for the studied electrode using jenway $\mathrm{pH}$ meter $3310 \mathrm{pH} / \mathrm{mV} / \square \mathrm{C}$ meter instead of Mettler Toledo automatic titrator.

The potential displayed by the proposed electrode for the measurements of the standard drug solution in the same day and linearity range from day-to-day does not vary by more than $\pm 1 \mathrm{mV}$. Calibration slopes didn't change by more than \pm 1 $\mathrm{mV} / \mathrm{dec}$ ade concentration over a period of 3 weeks. The required time for the sensor to reach values within $\pm 1 \mathrm{mV}$ of the final equilibrium potential after increasing the drug concentration 10-folds was found to be 10 seconds. Typical calibration plot is shown in Fig. 2. The slope of the calibration plot was 58.5 $\mathrm{mV} /$ concentration decades. The slight deviation from the ideal Nernstian slope $(60 \mathrm{mV})$ stems from the fact that the electrode responds to the activities of drug anion and cation rather than to their concentration. Nernstian relation of the sensor is: 


$$
E=-58.5 \log [C]+299.2
$$

where $[\mathrm{C}]$ is the molar concentration. The detection limit of the proposed sensor was estimated according to the IUPAC definition [27]. LOD value was found to be $10^{-6} \mathrm{~mol} \mathrm{~L}^{-1}$.

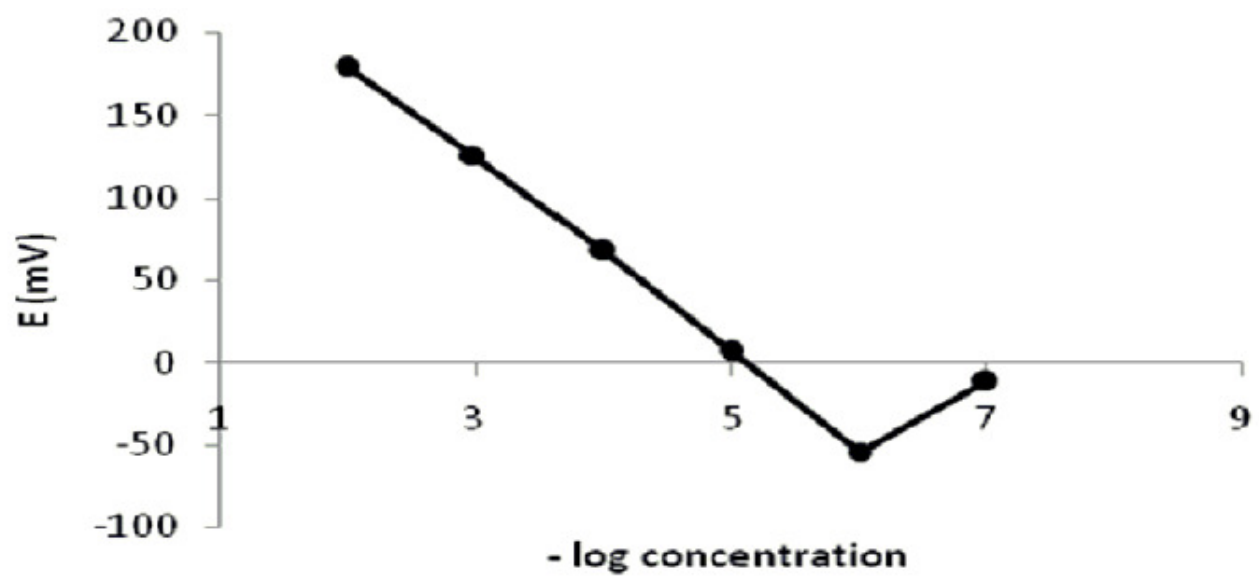

Figure 2. Profile of the potential in $\mathrm{mV}$ vs. $-\log$ concentration of $\mathrm{DPPH}^{\bullet}$ using the investigated $\mathrm{DPPH}^{*}$ sensor.

\section{The effect of $\mathrm{pH}$ and temperature}

The influence of $\mathrm{pH}$ on the potential response of the sensor was studied at different concentrations, $10^{-3}$ and $10^{-4} \mathrm{~mol} \mathrm{~L}^{-1}$ over the $\mathrm{pH}$ range 1-9; the potential $\mathrm{pH}$ profile (Fig. 3) indicated that the sensor potential is fairly constant over the $\mathrm{pH}$ range of 3-8, therefore, this range can be chosen as the working $\mathrm{pH}$ range for the sensor assembly; above $\mathrm{pH} 8$, the hydroxide anion reacts with $\mathrm{DPPH}^{\circ}$, in two ways, the first one in which the anion acts as a nucleophile and makes a complex, which decomposes after that by losing a hydride anion or a nitrite anion, leading to different compounds, or the $\mathrm{DPPH}^{*}$ is strong enough to abstract one electron from the anion and to oxidize it to the short-lived radical X, which reacts with $\mathrm{DPPH}^{*}$, yielding also finally the nitro derivative of $\mathrm{DPPH}^{\circ}$ [38], as shown in Fig. 4.

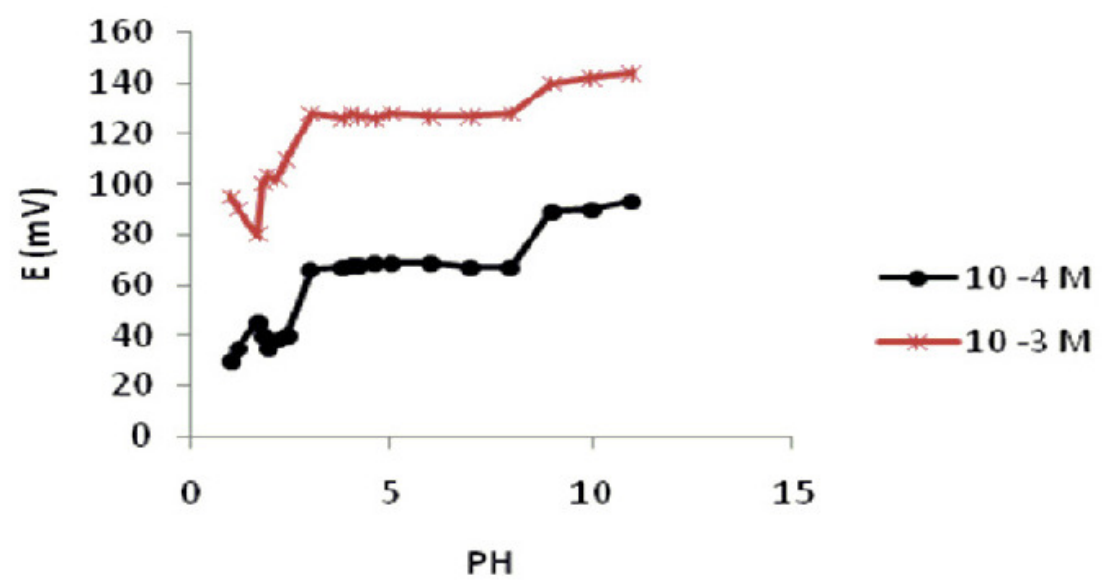

Figure 3. Effect of $\mathrm{pH}$ on the response of $\mathrm{DPPH}{ }^{*}$ sensor. 


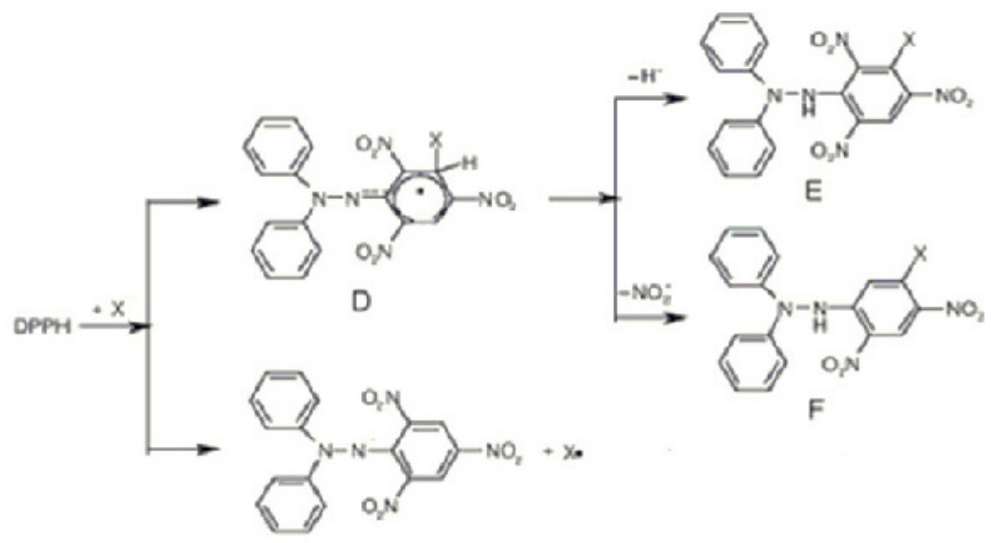

Figure 4. Reaction of DPPH with anion $\left(\mathrm{X}=\mathrm{OH}^{-}\right)$.

Upon studying the effect of temperature, the proposed sensor exhibits slight increase in its potentials as the temperature rises in the range of $25-40{ }^{\circ} \mathrm{C}$; however, the calibration graphs obtained at different temperatures were parallel, as shown in Fig. 5.

The limit of detection, slope and response time didn't significantly vary with variation of temperature, indicating reasonable thermal stability up to $40{ }^{\circ} \mathrm{C}$.



Figure 5. Effect of temperature on the response of $\mathrm{DPPH}^{\circ}$ sensor.

\section{Sensor selectivity}

Table 2 shows the potentiometric selectivity coefficients of the proposed sensor in the presence of other interfering substances. The results reveal that the proposed membrane sensor displays high selectivity.

Assessment of the antioxidant activity of paracetamol and dipyridamole in pure form, dosage forms and SIF

The radical scavenging activity was calculated as follows:

$$
\mathrm{I} \%=\left[\left(\mathrm{E}_{0}-\mathrm{E}_{1}\right) / \mathrm{E}_{0}\right] \times 100
$$


where $E_{0}$ is the potential of the control and $E_{1}$ is the potential in the presence of the test compound at different concentrations.

The $\mathrm{IC}_{50}$ values were calculated graphically by plotting the antioxidant drug concentration vs. the corresponding scavenging effect using the algorithm implemented in Microsoft Visual Basic ${ }^{\circledR} 6.0$ (Microsoft Corporation, Redmond, WA, USA) (on the basis of probit, logit and angular regressions) as presented in Fig. 6-8.

Table 2. Potentiometric selectivity coefficients $\left(\mathrm{K}^{\mathrm{pot}}\right)$ for the investigated $\mathrm{DPPH}^{\bullet}$ selective membrane sensor.

\begin{tabular}{|l|c|}
\hline Interferent $^{\mathrm{a}}$ & Selectivity coeffecient \\
\hline Sodium bicarbonate & $1.75 \times 10^{-3}$ \\
\hline Citric acid & $7.19 \times 10^{-3}$ \\
\hline Potassium chloride & $1.50 \times 10^{-3}$ \\
\hline Nickel chloride hexahydrate & $1.40 \times 10^{-2}$ \\
\hline Magnesium chloride & $2.53 \times 10^{-3}$ \\
\hline Paracetamol & $3.75 \times 10^{-3}$ \\
\hline Dipyridamole & $1.33 \times 10^{-3}$ \\
\hline BHA & $4.01 \times 10^{-3}$ \\
\hline
\end{tabular}

${ }^{a}$ Aqueous solutions of $1 \times 10^{-3} \mathrm{M}$ were used.

Table 3. $\mathrm{DppH}^{\circ}$ radical scavenging activity of the studied antioxidants.

\begin{tabular}{|c|c|c|}
\hline \multirow[t]{2}{*}{ Compound } & \multicolumn{2}{|c|}{$\mathrm{IC}_{50}$ concentration $^{\mathrm{a}}(\boldsymbol{\mu g} / \mathrm{mL})$ determined by } \\
\hline & Proposed sensor & Colorimetric method \\
\hline \multicolumn{3}{|l|}{ Pure antioxidants } \\
\hline BHA & $7.38 \pm 0.35$ & $7.40 \pm 0.12$ \\
\hline Paracetamol & $89.98 \pm 0.45$ & $90.05 \pm 0.60$ \\
\hline Dipyridamole & $1450.00 \pm 1.50$ & $1449.00 \pm 0.90$ \\
\hline \multicolumn{3}{|l|}{ Drug formulations } \\
\hline Hepamol $^{\circledR}$ & $90.05 \pm 1.07$ & $91.01 \pm 0.54$ \\
\hline Hepamol $^{\circledR}$ in SIF & $88.50 \pm 0.02$ & $89.11 \pm 0.64$ \\
\hline Persantin ${ }^{\circledR}$ & $1451.12 \pm 2.22$ & $1450.90 \pm 1.09$ \\
\hline Persantin $^{\circledR}$ in SIF & $1449.50 \pm 2.01$ & $1452.33 \pm 2.03$ \\
\hline
\end{tabular}

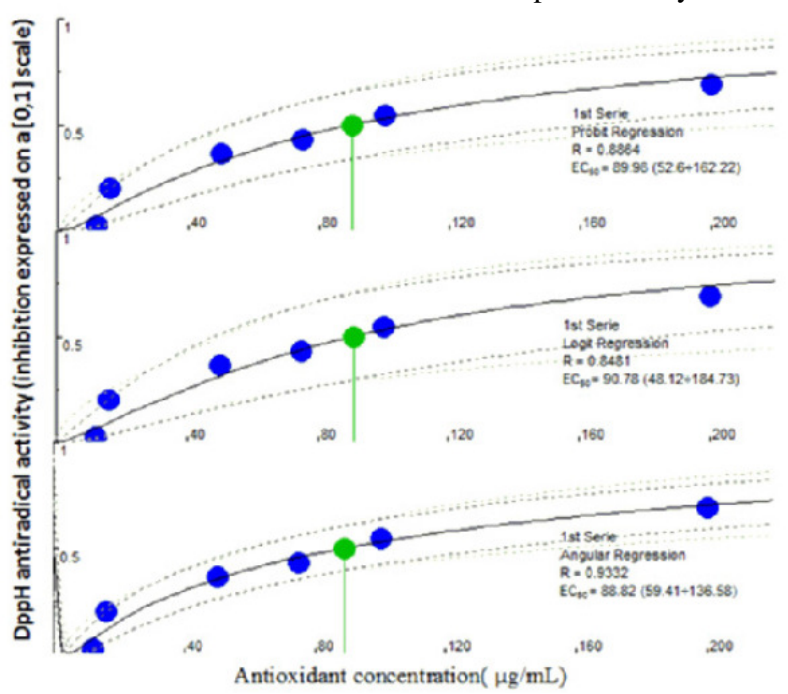

Figure 6. Antiradical activity curves obtained for paracetamol on the basis of probit, logit and angular regressions. 


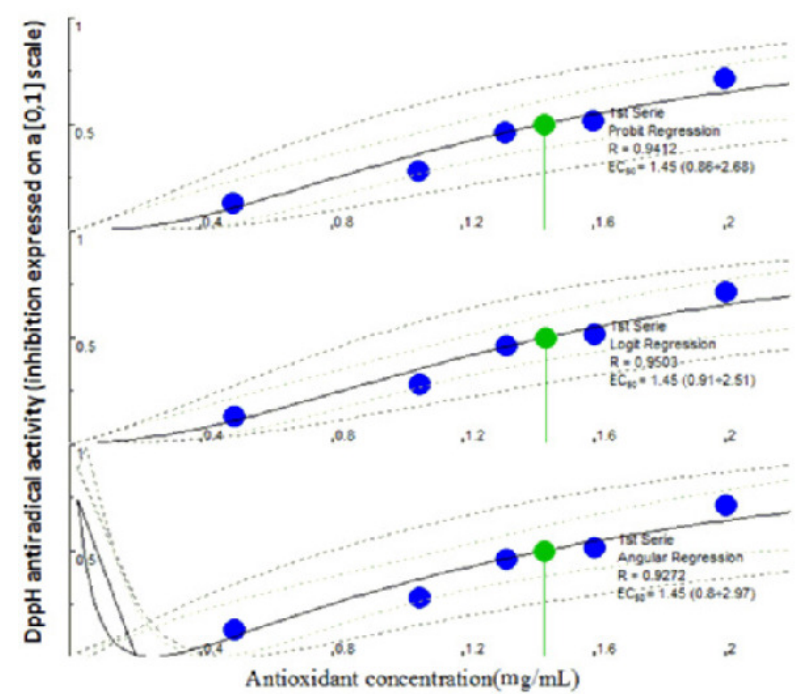

Figure 7. Antiradical activity curves obtained for dipyridamole on the basis of probit, logit and angular regressions.

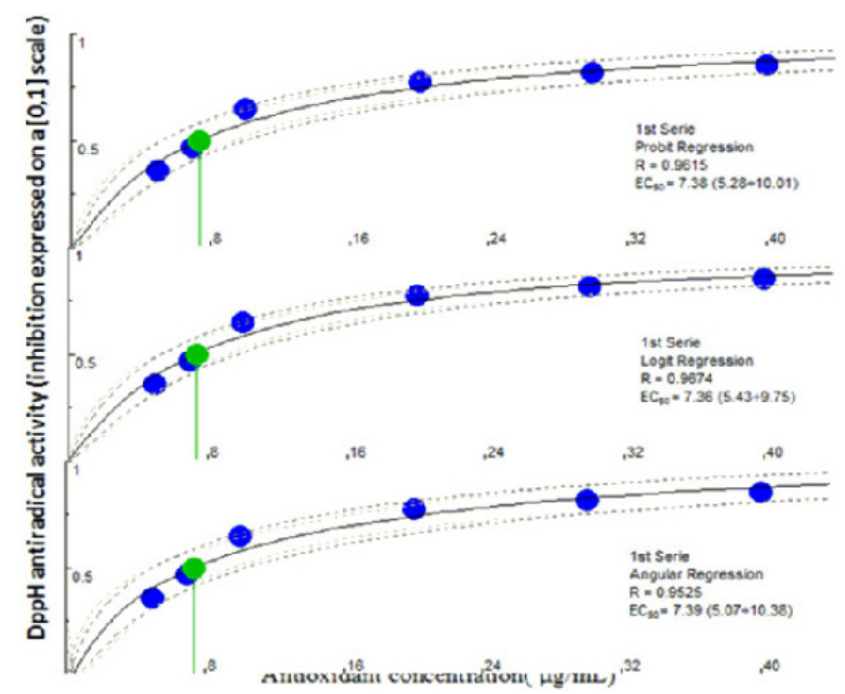

Figure 8. Antiradical activity curves obtained for BHA on the basis of probit, logit and angular regressions.

The proposed sensor was successfully used for evaluating the antioxidant activities. The percentage scavenging of $\mathrm{BHA}\left(\mathrm{IC}_{50}\right)=7.38 \mu \mathrm{g} / \mathrm{mL}$, paracetamol $\left(\mathrm{IC}_{50}\right)=89.98 \mu \mathrm{g} / \mathrm{mL}$ and dipyridamole $\left(\mathrm{IC}_{50}\right)=1.45 \mathrm{mg} / \mathrm{mL}$. Probit model had been chosen as it is well adapting to the data obtained from the DPPH assay and it generally gives the intermediate $\mathrm{IC}_{50}$ amongst the three regression models considered. Results arranged scavenging activity in the following order: BHA> paracetamol $>$ dipyridamole. The AAI value [final concentration of DPPH $^{\bullet}$ in $\left.\mu \mathrm{g} \cdot \mathrm{mL}^{-1} / \mathrm{IC}_{50}(\mu \mathrm{g} / \mathrm{mL})\right]$ of the standard antioxidant BHA is correlated well with that obtained from the application of the colorimetric method established by Gourine et al. [39] (Table 3).

The results proved the applicability of the proposed sensor for the evaluation of $\mathrm{DPPH}^{*}$ scavenging activity of the studied drugs in their pharmaceutical formulations and in SIF. 


\section{Conclusions}

The proposed membrane sensor was successfully used for assessment of $\mathrm{DPPH}^{\bullet}$ scavenging of paracetamol and dipyridamole in pure form and in dosage form in (SIF). It also offers moderate stability time, elimination of drug pretreatment or separation steps, wide $\mathrm{pH}$ range, low detection limit and direct determination of drugs scavenging effects in turbid and colored solutions without interference by pigments or excipients. In addition, $\mathrm{DPPH}^{*}$ radical is stable, commercially available, and does not have to be generated before assay.

The use of the proposed sensor is particularly suited to fast response and low-cost screening of the antioxidant activity.

\section{References}

1. B. Halliwell, J.M.C. Gutteridge, Free Radicals in Biology and Medicine, third ed., Oxford University Press, New York, 1999.

2. Balazs L, Leon M. Neurochem Res. 1994;19:1131-1137.

3. Lewen A, Matz P, Chan PH. Neurotauma. 2000;17:871-890.

4. Duh PD, Tu YY, Yen GC. Lebensmittel Wissenchaft und-Technologie. 1999;32:269-277.

5. Bautista AP, Mészáros K, Bojta J, et al. Leukocyte Biol. 1990;48:123-128.

6. Bautista AP, Spitzer JJ. Am J Physiol. 1990;259:907-912.

7. CRC press, Taylor and Francis group, oxidative stress and inflammatory mechanisms in obesity, diabetes and metabolic syndrome, Lester Packer, Helmut Sies, 2007.

8. Magalhães LM, Segundo MA, Reis S, et al. Anal Chim Acta. 2008;613:119.

9. Gülcin I. Life Sci. 2006;78:803-811.

10. Gourine N, Yousfi M, Bombarda I, et al. Ind Crops Products. 2010;31:203208.

11. Beara IN, Lesjak MM, Četojević-Simin DD, et al. Food Res Int. 2012;49:501-507.

12. Tadhani MB, Patel VH, Subhash R. Food Compos Analysis. 2007;20:323329.

13. Blois MS. Nature. 1958;181:199-206.

14. Milardovic S, Ivekovic D, Grabaric BS. Bioelectrochem. 2006;68:175-180.

15. Milardovic S, Ivekovic D, Ruwenjak V, et al. Electroanalysis. 2005; 17:1847-1853.

16. Ciesla Ł, Kryszen J, Stochmal A, et al. Pharm Biomed Anal. 2012;70:126135.

17. Chandrasekar D, Madhusudhana K, Ramakrishna S, et al. Pharm Biom Anal. 2006;40:460-464.

18. Shi S, Ma Y, Zhang Y, et al. Sep Purif Tech. 2012;89:225-233.

19. Qiu J, Chen L, Zhu Q, et al. Food Chem. 2012;135:2366-2371.

20. Yamaguchi T, Takamura H, Matoba T, et al. Biosci Biotech Biochem. 1998;62:1201-1204. 
21. Magalhães LM, Santos M, Segundo MA, et al. Talanta. 2009;77:15591566.

22. Ukeda H, Adachi Y, Sawamura M, Talanta. 2002;58:1279-1283.

23. Polasek M, Skala P, Opletal L, et al. Anal Bioanal Chem. 2004;379:754758.

24. Koleckar V, Opletal L, Brojerova E, et al. J Enzym Inhib Med Chem. 2008;23:218-224.

25. Magalhães LM, Segundo MA, Reis S, et al. Anal Chim Acta. 2006;558:310-318.

26. Steinberg IM, Milardović S. Talanta. 2007;71:1782-1787.

27. Umezawa Y, Buhlmann P, Umezawa K, et al. Pure Appl Chem. $2000 ; 72 ; 1851$.

28. Locatelli M, Gindro R, Travaglia F, et al. Food Chem. 2009;114:889-897.

29. Sharififar F, Moshafi MH, Mansouri SH, et al. Food Control. 2007;18:800805.

30. Gülcin I, Beydemir S, Lici HA. et al. Pharm Res. 2004;49:59-65.

31. Loftsson T, Brewster ME. Pharm Sci. 1996;85:1017-1025.

32. Adhikari B, Majumdar S. Prog Polym Sci. 2004;29:699-766.

33. Cunningham AJ. Introduction to bioanalytical sensors. New York:Wiley; 1998. p. 113.

34. Stefan R, Staden JV, Aboul- Enein H. Talanta. 1999;48:1139-1143.

35. Foti MC, Daquino C, Geraci C. J Org Chem. 2004;69:2309-2314.

36. Magalhães LM, Segundo MA, Siquet $C$, et al. Microchim Acta. 2007; 157:113-118.

37. Stasko A., Brezova V., Biskupic S., et al. Free Rad Res. 2007;41:379-390.

38. Ionita P. Chem Pap. 2005;59:11-16.

39. Gourine N., Yousfi M., Bombarda I., et al. Ind Crops Prod. 2010;31:203208. 